\title{
Effect of Hydrogen on Corrosion Behavior of S32750 Super Duplex Stainless Steel
}

\author{
Yier Guo, Ping Liang ${ }^{*}$ Yanhua Shi, Yan Zhao, Fei Li, Lan Jin
}

School of Mechanical Engineering, Liaoning Shihua University, Fushun 113001, China *E-mail: liangping770101@163.com

doi: $10.20964 / 2018.11 .44$

Received: 13 July 2018/ Accepted: 1 September 2018 / Published: 1 October 2018

Electrochemical behaviors and critical pitting temperature (CPT) of S32750 super duplex stainless steel (SDSS) in 3.5\% NaCl solution with various hydrogen charging current densities (HCCD) were investigated by using open-circuit potential (OCP) curves, potentiodynamic polarization curves, electrochemical impedance spectroscopy (EIS), Mott-Schottky curves, and the potentiostatic polarization curves electrochemical measurements methods. Results showed that the open-circuit potential and self-corrosion potential gradually shift negatively, the passivity current density increases, pitting corrosion potential and self-corrosion potential decreases with the increase of the hydrogen charging current density from $10 \mathrm{~mA} \cdot \mathrm{cm}^{-2}$ to $100 \mathrm{~mA} \cdot \mathrm{cm}^{-2}$. Slope of the Mott-Schottky curves and the CPT gradually decreases as HCCD increased. As compared with the blank specimen, it is indicated that hydrogen leads to the delay of the passivation film formation and the reduction of the stability and integrity of the passivation film. The passivation film is more prone to cracking and dissolution, therefore, the corrosion of S32750 SDSS is more likely to occur after the hydrogen is charged.

Keywords: Hydrogen Charge Current Density, S32750 Super Duplex Stainless Steel, Critical Pitting Temperature

\section{FULL TEXT}

(C) 2018 The Authors. Published by ESG (www.electrochemsci.org). This article is an open access article distributed under the terms and conditions of the Creative Commons Attribution license (http://creativecommons.org/licenses/by/4.0/). 